Dept. of Pathology, Animal Health Research Institute, Alexandria Regional Laboratory.

\title{
CLINICAL AND PATHOLOGICAL STUDIES ON KIDNEY LESIONS IN BROILER CHICKENS
}

(With 2 Figures)

\author{
By \\ SANAA ABDOU EL-SHAMY
}

(Received at 14/3/2011)

دراسات اكلينيكية وباثولوجية على الآفات الكلوية فى دجاج التسمين

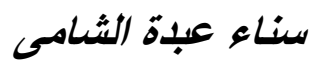

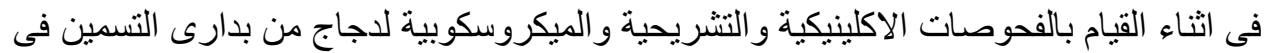

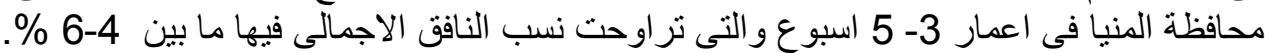

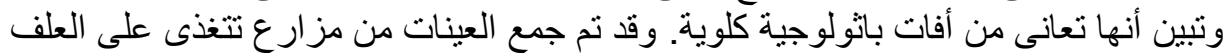



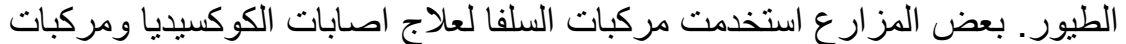

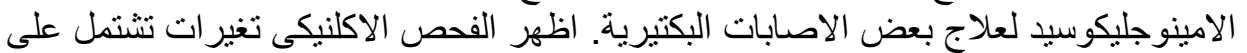

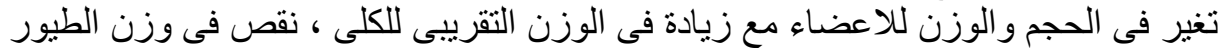

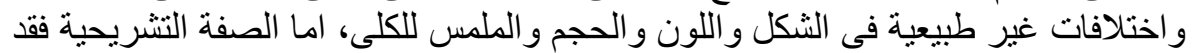





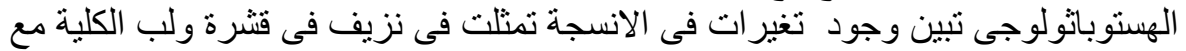

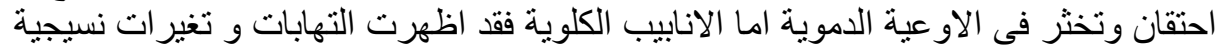

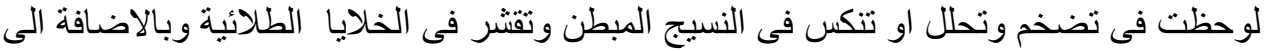

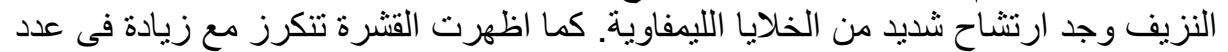

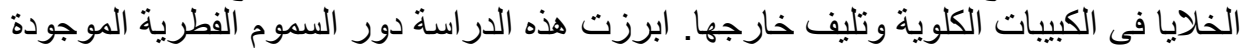

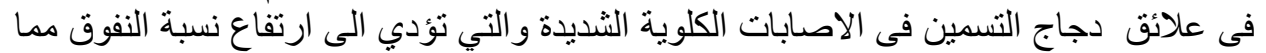
يؤدى الى خسارة اقتصادية كبيرة.

\section{SUMMARY}

Kidney lesions were detected histopathologically during clinical and postmortem examinations of broilers from private farms in El-Minia Governorate. The birds were 3-5 weeks old and the average mortality allover the cycle was 4-6\%. Pellted feeds were used in all farms. Birds 
were vaccinated against Infectious bronchitis, New Castle disease, Gumboro and Avian Influenza. Some of the examined cases were treated with Sulfonamindes and Gentamycine for controlling of coccididia and Gram -negative bacteria, respectively. Examination of the kidneys revealed various abnormalities including variation in size and weight of the organ, increasing the relative weight of kidneys, reducing the body weight gain of the birds, abnormalities of color, shape, size and texture with haemorrhage. Histopathologically, the kidneys showed haemorrhages in cortex and medulla, congestion and thrombosis. The renal tubules showed signs of nephrosis in form of swelling, degeneration and desquamation of the lining epithelium, heavy infiltration of the renal cortex with lymphocytes and heterophiles, and coagulative necrosis. Some cases showed swelling and hypercellularity of the glomeruli with periglomerular fibrosis. It had been concluded that mycotoxins present in broiler feedstuffs have a deleterious effect on the kidneys. Considering that the kidneys are one of the vital organs, there was an increase in the mortality rate and high economic losses.

Key words: Pathology, kidney lesions, broilers.

\section{INTRODUCTION}

The kidney is considered an important organ in the chicken's body that responsible for diverse metabolic and execratory functions, maintaining the chemical composition of body fluid, removal of metabolic waste and toxic products, regulation of blood pressure and blood volume and conservation of fluid and electrolytes (Qureshi, 2003).

There is an increase involvement of kidney lesions in a number of diseases. They can recognize from case history, environmental condition and the post-mortem examination as help in conclusive diagnosis. Studying of the gross and microscopic pictures is very important because there is a strong relationship between the kidney lesions and several diseases. Also, there is relationship between the kidney lesions and poultry feeding including balanced ration and salt intake and vitamins (Siller, 1981; Guo et al., 2005).

Generally, poultry are very sensitive to mycotoxins and the effects vary by species and sex. Small quantity of myctoxins in feed can cause increased mortality, reduction in weigh gain, feed intake and egg production (Cirish et al., 2008). Many mycotoxins elicit acute, chronic and 
subchronic toxicological manifestations in human and susceptible animals depending on the concentration and duration of exposure to the toxin and on the age and nutritional state of the animal (Wood, 1992).

The present study was conducted to study the correlation between the pathologic changes of kidneys with causative agent. Correct identification of cause help in prevention and control programme which is necessary to reduce the economic losses till the time solution is found.

\section{MATERIALS and METHODS}

During the period from January to December 2010, fifteen commercial broiler private farms (5000- 10000 chickens each) in El Minia Governorate were examined clinically and grossly. Pellted feeds were used for all farms. Birds were vaccinated against Infectious Bronchitis, New Castle disease, Gumboro, and Avian Influenza. Some of examined cases were treated with sulfonamindes and Gentamycine for controlling of coccididia and Gram -negative bacteria, respectively. Broilers, at 3-5 weeks old, showing 4-6\% mortality allover the cycle.

For histopathological examination, tissue specimens were obtained from kidneys. Specimens were fixed in $10 \%$ neutral buffered formalin, dehydrated in a graded alcohol series, cleared with methyl benzoate and embedded in paraffin wax. Sections of $5 \mu \mathrm{m}$ were cut and stained with haematoxylin/eosin for light microscopic examination (Bancroft and Stevens, 1996).

For detection and estimation of different mycotoxins in feedstuffs commonly used in poultry feeding, samples of each feed ingredient (yellow corn, barley, corn gluten, soy bean meal, wheat bran, broiler concentration, blood meal and bone meal) were taken. Samples were defatted by extraction with cyclohexane for 10 hours using Soxhlet type extractor. The defatted residue was extracted for anther 10 hours with chloroform. The chloroform extract was dried over anhydrous sodium sulphate, filtered and then distilled under vacuum to near dryness. The residue was diluted with chloroform to one $\mathrm{ml}$. Chromatographic analysis of chloroform extracts was achieved for the presence of mycotoxins according to Scott et al. (1970); Roberts and Patterson (1975). 


\section{RESULTS}

Chromatographic analysis of chloroform extract of all samples of common poultry feedstuffs showed that corn, corn gluten, barley, broiler concentration and Soya bean were naturally contaminated with mycotoxins.

\section{Clinical Signs:}

The examined birds showed dullness, weakness, anorexia, reduced feed intake, loss of body weight, diarrhea, increased mortality and haemorrhages in the kidneys.

\section{Post - mortum Examination:}

Kidney abnormalities included variation in size and weight of the organ, increasing the relative weight of kidney, reducing the body weight gain of the birds. Gross lesions were mainly confined to the kidneys which appeared pale swollen or enlarged with haemorrhages and showed evidence of sever ureate deposits.

Some dead and alive chicks showed enlarged, elongated lobulated kidneys and distended ureters with chalky white crystal impaction. Similar chalky white crystal depositions were also noticed grossly on some of the visceral organs like liver and heart and visceral mesenteries.

\section{Histopathological examination:}

The kidneys showed haemorrhages in cortex and medulla. Congestion and thrombosis of the blood vessels were noticed (Figs. 1a, b). The renal tubules showed signs of nephrosis in the form of swelling, degeneration and desquamation of the lining epithelium (Figs. 1c, d).

In addition to haemorrhages, heavy infiltrations of the renal cortex with lymphocytes were seen (Fig. 2a). Lymphocytic inflammatory infiltrates extended to the renal medulla. The renal tubules revealed coagulative necrosis of cytoplasm and nuclear karyorrhexis (Fig. 2b). Some cases showed swelling and hypercellularity of the glomeruli with periglomerular fibrosis (Fig. 2c). 

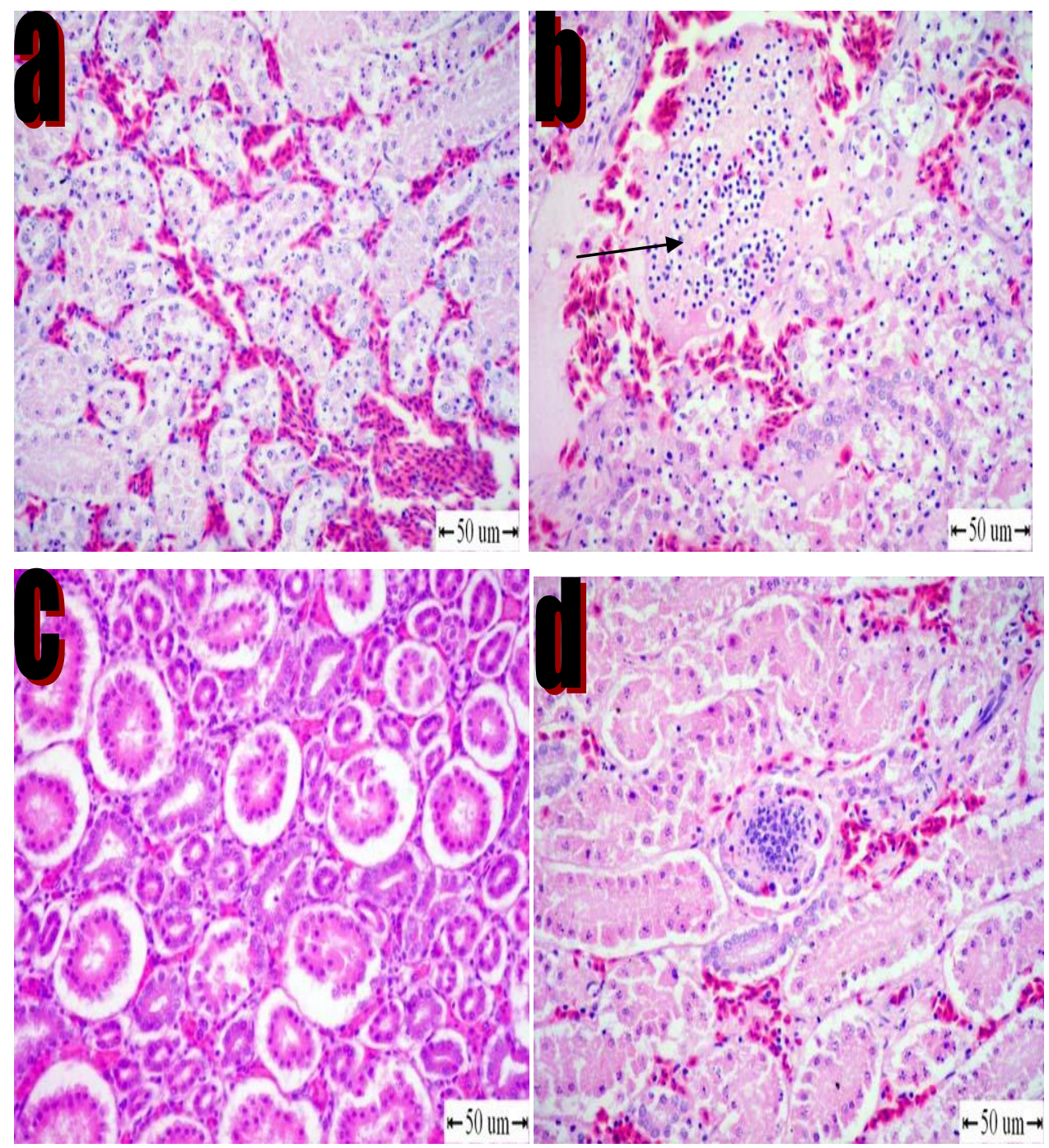

Fig. 1: (a, b) Kidney of chicken showing cortical and medullary haemorrhage and thrombosis (arrow) X25.

(c) Swelling and desquamation of the renal tubuler epiheliumX40.

(d) Degeneration and desquamation of the lining epithelium X40. HE. 



Fig. 2: (a) Kidney tissue showing haemorrhage and heavy infiltration of mononuclear cells X25.

(b) Kidney parenchyma infiltrated with mononuclear cells X40.

(c) Swelling and hypercellularity of the glomerular tuft (arrows) X40. HE. 


\section{DISSCUTION}

The incidence of kidney lesions in broiler birds occur due to multietiological factors. These causes can be categorized as nutritional or metabolic, infectious, toxic (Beckman and Bernie 2003; Patel et al., 2007; Banday et al., 2009). Toxic causes include mycotoxins, antibiotics, oosporein and disinfection (Beasley 1999 ).

In the present study, from history of examined cases, necropsy and histopathological findings results directed towards the toxicity of mycotoxicosis. Mycotoxins contamination of feeds appears to be on increase globally. Nephrotoxicity has been reported in several species and the kidneys appear to be the most target (Bucci et al., 1998).

Recently, Qureshi (2003) reported that the problem of mycotoxins in feed has caused heavy losses in broiler and layer flocks due to lesions of hepato- nephrosis. Kidneys are invariably affected, showing swelling and haemorrhages. Kubena et al. (1995) reported that fed diet containing mycotoxins affected chicks from day to hatch to 21 days of age and he found that relative weights of kidneys increased and the efficiency of feed utilization was reduced. Our results were similar to those mentioned above, but the affected birds were 3-5 weeks old, average mortality allover the cycle was 4-6\%.

Mathieu et al. (2008); Jayabarathi and Mohamudha (2010) observed that, in poultry, the contamination with mycotoxins lead to fatty liver, kidney disorder, leg and bone problems, reduced hatchability, small eggs, vaccine failure and reduced immunity, lowered resistance to diseases, bacteria and viruses and reduced performances (weight gain, FCR and mortality). In the present study, the gross lesions mainly confined to the kidneys which appeared pale swollen with haemorrhages and showed evidence of sever ureate deposit. In our opinion accumulation of uric acids in the blood and its deposition in the kidney was due important kidney function due to impaired kidney function due to the damging effect of amycotoxine on the renal parenchyma.

Histopathologically, the kidneys showed haemorrhages in cortex and medulla. Congestion and thrombosis of the blood vessels. The renal tubules showed signs of nephrosis in the form of swelling, degeneration and desquamation of the lining epithelium. Dwivedi and Burns (1984); Hanif et al. (2008) reported that mycotoxins are the most serious for poultry, the kidneys showed degenerative changes in the epithelial cells of proximal convoluted tubules, massive necrosis of distal convoluted tubules epithelium (Santin et al., 2002). Brawn et al. (1987) found that, in broiler chicks, a mycotoxin is potent nephrotoxin causing proximal tubular 
nephrosis, thickened glomerular capillary basement membranes, abnormal mitochondrial shapes, increased size of proximal convoluted tubular epithelium, necrosis of distal convoluted tubules. Bucci et al. (1998) observed that the morphologic change principally affects the junction of cortex and medulla, and includes prominent apoptosis of epithelial cells of proximal convoluted tubules.

It is worthy to mention, that the biggest concern for poultry producers in the year 2010 will be the contamination of corn with mould and mycotoxins (Smith, 2010). The results obtained in this study suggested higher risk for human health because the possibility of indirect exposure through poultry tissue and products. Therefore, the contamination of mycotoxins in poultry feeds should be reduced by good manufacturing and good storage practices. Monitoring of mycotoxins in poultry feeds is especially important because it not only provides a healthier diet for poultry, but it also may indirectly prevent any mycotoxin residue carry over in poultry for human consumption. (Hussein and Brasel, 2001; Yegani et al., 2001).

It had been concluded that mycotoxins present in the foods stuffs have a deleterous effect on the kidneys, considering that the kidneys is one of the vital organs, there was an increase in the mortality rate and hence a high economic losses. We advice that monitoring of mycotoxins in poultry feeds is very important.

\section{REFERENCES}

Bancroft, J.D. and Stevenson, A. (1996): Theory and practice of histological techniques. Churchill Livingstone. Edinburgh, London, Melbourne and New York.

Banday, M.T.M.; Mukesh, B.; Sheikh, A. and Sringar, Kashmir (2009): India avian gout, causes and treatment and prevention. www.engormix.com.

Beasly, V. (1999): Nephrotic Mycotoxin Dept. of Vet. Bioscience, College of Vet. Medicine, University of Illionis at Urpana-Champaign, USA-online atwww.ivis.org document no. a2619.0899.

Beckman, Dr. Bernie (2003): Avian urolethiasis (gout) A puplication of Highline., www. highline.com.

Brawn, T.P.; Fletcher, O.J.; Osuna, O. and Wyatt, R.D. (1987): Microscopic and ultrastructured renal pathology of oosporein induced toxicosis in broiler chicks. Avain Diseases, 31: 868-877. 
Bucci, T.Y.; Howard, P.C.; Tolleson, W.H.; Laborde, J.B. and Hansen, D.K. (1998): Renal effect of fumonsin mycotoxins in animals. Pathology Associates International, Jeffcison, Arkansas 71079. U. S. A. Toxic Pathology 26(1): 160-164.

Cirish, C.K.; Smith, T.K.; Boermans, H.J. and Karrow, N.A. (2008): Effect of feeding blends of grains naturally contaninted with fusarium mycotoxins on performance hematology, metabolism and immunocompatence of turkey. Poultry Sci., 87: 421-432.

Dwivedi, P. and Burns, R.B. (1984): Pathology of ochratoxosis A in young broiler chicks. Research Vet. Sci. J.36(1): 92-103.

Guo, X.; Huang, K. and Tang, J. (2005): Clinicopathology of gout in growing layers induced by high calcium and high protein diets. Br. Poultry Sci., 46, 5: 641-646.

Hanif, N.Q.; Muhammed, Siddique M.; Khanum, A.; Ahmed, T. and Kaukab, G. (2008): Clininico- pathomorphlogical, serum biochemical and histological studies in broilers feed ochratoxin A and a toxin deactrator. Br. Poultry Sci. Sep 49(5): 632-642.

Hussein, H.S. and Brasel, J.M. (2001): Toxicity, metabolism and impact of mycotoxins on humans and animals. Toxicology 167: 101-134.

Jayabarathi, P. and Mohamudha, P.R. (2010): Biochemical and histopathological analysis of aflatoxicosis in growing hens with commercial poultry feed. International Journal of Pharmaceutical Sciences Review and Research, 3, 2: 127-130.

Kubena, L.F.; Edrington, T.S.; Kamps, Hottzapple, C.; Harvey, R.B.; Elissalde, M.H. and Rottinghurs, G.E. (1995): Effect of feeding fumonisin B present in fusorium moniliforme culture materical of aflatoxin singly and in combination to turkey poults. Poultry Sci., 74: 1295-1303.

Mathieieu, G. and Impextraco, N.V. (2008): Singapore representative office Mathieu @impentraco com., Mycotoxins in Animal nutration -problems and solution.

Qureshi, A.A. (2003): Kidney lesions in poultry diseases. Poultry Diagnosis and Research Institute, Karachi. www. wat. net.com.

Patel, A.K.; Ghodasara, D.J.; Dave, C.J.; Jani, P.B.; Joshi, B.P. and Parajapati, K.S. (2007): Experimental studies on etiopathology of visceral gout in broilers chicks. Indian Journal of Vet. Pathology. 31, 1: 0250-4758.

Roberts, B.A. and Patterson, D.S.P. (1975): Detection of twelve mycotoxins in mixed animal feedstuffs, using a noval membrane clean up procedure. J. Assoc. Office. Chem. 58: 1178-1181. 
Santin, E.; Palullillo, Ac.; Maiorka, P.C.; Allessi, A.C. and Krabbe, E.L. (2002): The effect of ochratoxin ,aluminosilicate interaction on tissues and humoral immune response of broiler Avian Pathology. 2002 .31(1): 73-90.

Scott, P.M.; Lowrence, J.W. and Van Walbeak, W. (1970): Detection of mycotoxins by thin layer chromatography application to screening of fungal extracts. Appl. Bolism Microbiology, 20: 839-842.

Siller, W.G. (1981): Renal pathology of fowl a review. Avian Pathology, 10: $188-261$.

Smith, K. (2010): Threat of mycotoxins to poultry in North America at the poultry informed professional Issue $110 \mathrm{www}$. Avian.uga -edu under the online Documents and the poultry informed professional links.

Wood, G.E. (1992): Mycotoxins in foods and feeds in United States. J. Anim. sci.70: 3941-3949.

Yegani, M.T.; Smith, K.; Lesson, S. and Boermans, H.J. (2006): Effect of feeding grains naturally contaminated with Fusarium mycotoxins on performance and metabolism of broiler breeders Poult. Sci 85: 1541-1549. 

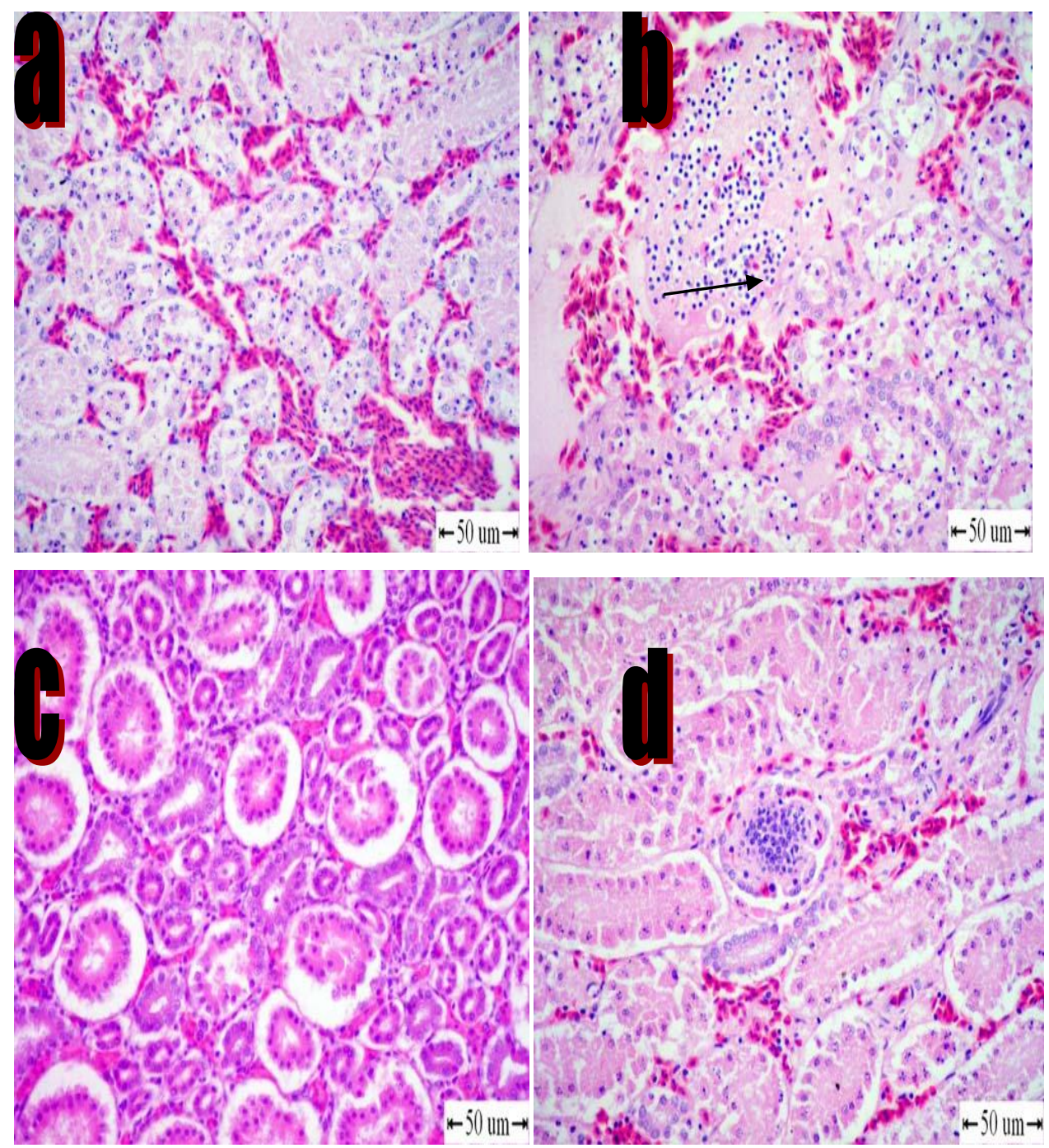

Fig. 1: (a, b) Kidney of chicken showing cortical and medullary haemorrhage and thrombosis (arrow) X25. c) Swelling and desquamation of the renal tubuler epiheliumX40.

(d) Degeneration and desquamation of the lining epithelium X40. HE. 
Assiut Vet. Med. J. Vol. 57 No. 129 April 2011 

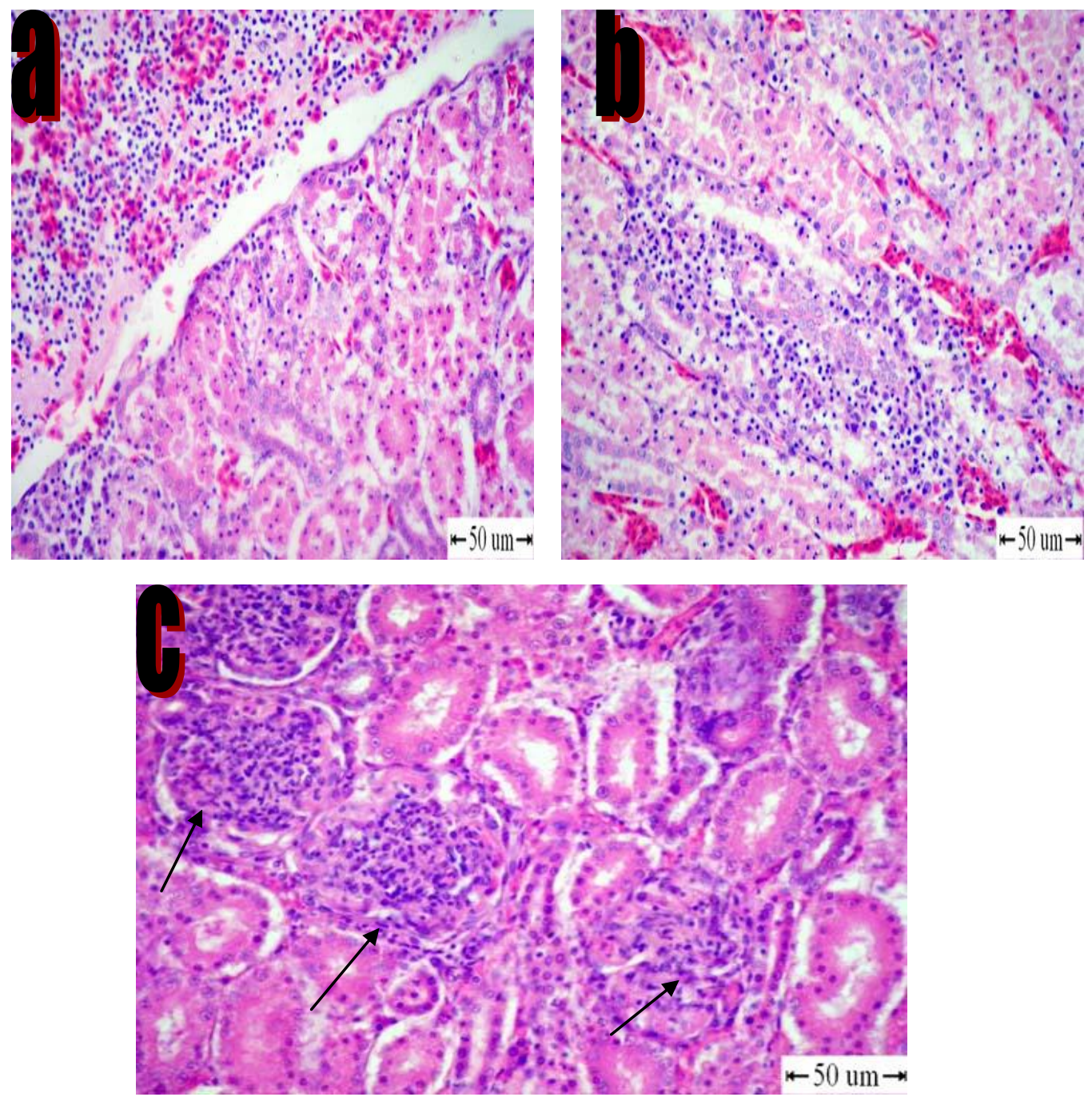

Fig. 2: (a) Kidney tissue showing haemorrhage and heavy infiltration of mononuclear cells X25. (b) Kidney parenchyma infiltrated with mononuclear cells X40. (c) Swelling and hypercellularity of the glomerular tuft (arrows) X40. HE. 